\title{
UTILITY OF ENAMINONITRILE IN THE SYNTHESIS OF NOVEL HETEROCYCLES BEARING PYRAZOLE MOIETY AND THEIR ANTIMICROBIAL AND CYTOTOXIC ACTIVITY ASSESSMENT
}

\author{
GALAL H. SAYED ${ }^{1}$, MOHAMMAD E. AZAB ${ }^{*}$, NABIL A. NEGM ${ }^{2}$ AND KURLS E. ANWER ${ }^{1}$
}

Departments of ${ }^{I}$ Organic Chemistry Lab., Chemistry, Faculty of Science, Ain Shams University, ${ }^{2}$ Petrochemical, Egyptian Petroleum Research Institute

\section{ABSTRACT:}

Enaminonitrile derivatives $1 a, b$ were used as a versatile material for the synthesis of different heterocyclic compounds such as pyrazoloacetamide, pyrazolopyrimidinone, pyrazolobenzamide, pyrazolopyrimidines, pyrazolothiazinethiones, pyrazolopyrimidinedithiones, pyrazolocyanoacetamide, pyrazolopyrazoles, tetrazolopyrazoles, pyrazolotetrazolopyrimidines, and pyrazolotetrazolodiazepine derivatives, through the reaction with different electrophiles and nucleophiles. The newly synthesized compound were tested against gram positive and gram negative bacteria, fungi and two human tumor cell lines.

Keywords: pyrazolopyrimidine, pyrazolothiazinethiones, pyrazolotetrazolopyrimidines, pyrazolotetrazolodiazepine, antimicrobial, cytotoxic activity.

\section{INTRODUCTION:}

In the last several decades, pyrazole derivatives have received considerable attention due to their wide-range of biological activity. Pyrazoles are reported to exhibit antiviral ${ }^{[1]}$, antagonist ${ }^{[2]}$, antimicrobial ${ }^{[3]}$, anti-bacterial ${ }^{[4]}$, anticancer ${ }^{[5]}$, anti-inflammatory ${ }^{[5]}$, analgesic ${ }^{[6]}$, anti-prostate cancer ${ }^{[7]}$, herbicidal ${ }^{[8]}$, acaricidal and insecticid-<smiles>C[C@@H](Oc1cc(-c2cnn(C3CCNCC3)c2)cnc1N)c1c(Cl)ccc(F)c1Cl</smiles>

For the above mentioned biological activity and in continuation of our efforts in the synthesis of biologically active heterocycles [13-17], we prepared an enaminonitriles containing pyrazole moiety, which were subjected to electrophilic and nucleophilic reactions in order to prepare novel heterocyclic compounds and study their antimicrobial and anticancer activities. The al ${ }^{[9]}$ activities and also as anti-Tobacco Mosaic Virus ${ }^{[10]}$.

Among pyrazoles, Crizotinib is a drug used as anti-cancer ${ }^{[1]}$, Cefoselis is a drug used as antibacteria ${ }^{[11]}$ and Celebrex (celecoxib) is a drug used for rheumatoid arthritis and osteoarthritis $^{[12]}$.

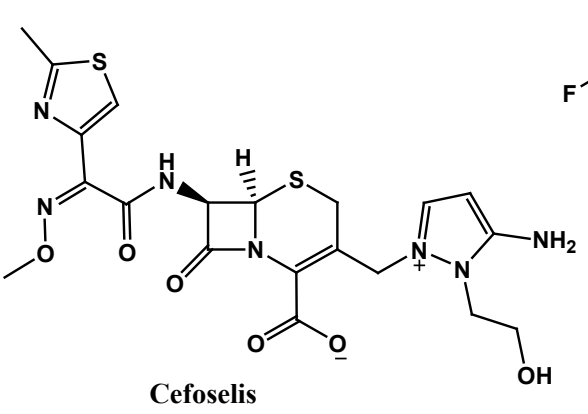

newly synthesized compounds were evaluated against gram positive Staphylococcus aureus, Bacillus subtilis and gram negative Escherichia coli, Pseudomonas aeuroginosa. The anti-fungal activities of the compounds were tested against two fungi Candida albicans, Aspergillus flavus. Also, some of the compounds were tested against two human tumor cell lines namely; mammary 
gland breast cancer (MCF-7) and human skin cancer (HFB4) some of the tested compounds showed high antimicrobial and cytotoxic activities.

\section{RESULTS AND DISCUSSION}

The starting enaminonitriles $1 \mathrm{a}, \mathrm{b}$ were prepared malononitrile, phenyl hydrazine and aromatic aldehydes in one pot reaction [18]. Compound 1a was treated with acetic anhydride, $\mathrm{Ac}_{2} \mathrm{O} / \mathrm{AcOH}$ mixture, benzoyl chloride in the presence of triethyl amine and/or phthalic anhydride producing N,N-diacetyl pyrazole, pyrazolopyrimidine, N-benzoyl pyrazole and 1,3-dioxoisoindolinyl pyrazole derivatives 2-5, respectively (Scheme 1).<smiles>CC(=O)N(C(C)=O)c1c(C#N)c([AlH2])nn1-c1ccccc1</smiles>

(b)<smiles>Cc1nc2c(c(Br)nn2-c2ccccc2)c(=O)[nH]1</smiles><smiles>N#Cc1c(Br)nn(-c2ccccc2)c1NC(=O)c1ccccc1</smiles><smiles>CCCCC(=O)n1c(=O)c2ccccc2n2nc(Br)c(C#N)c12</smiles>

Reagents and conditions: a) $\mathrm{Ac}_{2} \mathrm{O}$, reflux $3 \mathrm{~h}$, b) $\mathrm{Ac}_{2} \mathrm{O}, \mathrm{AcOH}$, reflux $\left.7 \mathrm{~h}, \mathrm{c}\right) \mathrm{PhCOCl}$, TEA, reflux $8 \mathrm{~h}$, d) Phthalic anhydride, AcOH, reflux $4 \mathrm{~h}$.

Scheme 1

Formation of compound 2 takes place through the reaction of the amino group with two moles of acetic anhydride. The ${ }^{1} \mathrm{H}-\mathrm{NMR}$ of 2 indicated the presence of a two acetyl groups where it showed $\delta$ at $2.18\left(\mathrm{~s}, 6 \mathrm{H} .2 \mathrm{COCH}_{3}\right)$. While compound 3 is believed to take place through the hydrolysis of the cyano group to amide group and acetylation of the amino group followed by ring closure through elimination of water molecule to produce the pyrimidinone ring. The structure of the product gets support from its IR spectrum which devoid of cyano group absorption band.

The structure of compound 4 was elucidated from its IR which showed peaks at $3287(\mathrm{NH})$, $2228(\mathrm{CN})$, and $1654(\mathrm{C}=\mathrm{O})$, and the ${ }^{1} \mathrm{H}-\mathrm{NMR}$ which displayed signals at $\delta: 7.49-8.88(\mathrm{~m}, 19$ $\mathrm{H}, \mathrm{Ar}-\mathrm{H}), 9.65$ (s, 1H, NH, $\mathrm{D}_{2} \mathrm{O}$ exchangeable). Also, the IR spectrum of compound 5 showed a peak at $1698(\mathrm{C}=\mathrm{O})$ and its MS: $\mathrm{m} / \mathrm{z} 490\left[\mathrm{M}^{+}\right]$ $(2.43 \%)$, which is in accordance with the structure.

On the other hand, reaction of 1a with 4-methoxybenzaldehyde, in the presence of catalytic amount of acetic acid, afforded the Schiff base 6 , while the reaction of $1 \mathrm{a}, \mathrm{b}$ with benzaldehyde in the presence of sodium hydroxide [19] pro- 
duced the pyrazolopyrimidine derivatives $7 \mathrm{a}, \mathrm{b}$. Also, refluxing 1a,b with carbon disulfide gave the pyrazolothiazine derivatives $8 \mathrm{a}, \mathrm{b}$, but when the same reaction was carried out in the presence of potassium hydroxide the pyrazolopyrimidine derivatives 9a,b were obtained ${ }^{[20]}$ (Scheme 2).

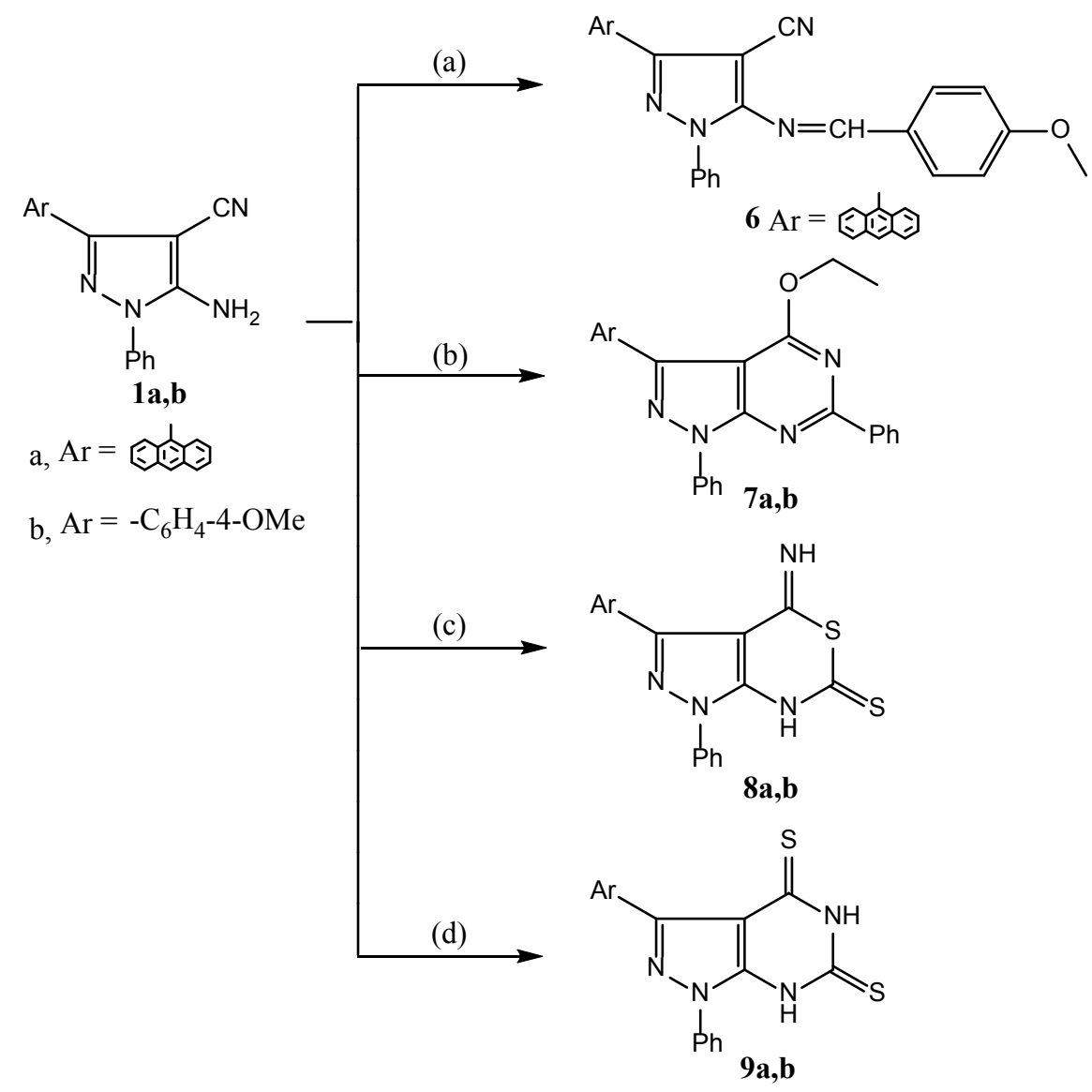

Reagents and conditions: a) $4-\mathrm{OMeC}_{6} \mathrm{H}_{4} \mathrm{CHO}, \mathrm{AcOH}$, reflux $3 \mathrm{~h}$, b) $\mathrm{C}_{6} \mathrm{H}_{5} \mathrm{CHO}, \mathrm{NaOH}$, reflux $2 \mathrm{~h}$, c) $\mathrm{CS}_{2}$, reflux $\left.2 \mathrm{~h}, \mathrm{~d}\right) \mathrm{CS}_{2}, \mathrm{NaOH}$, reflux $12 \mathrm{~h}$.

\section{Scheme 2}

The presence of the azo methine proton at $\delta$ 8.88 indicated the structure of the Schiff base 6. While compound 7a was approved by: its IR which devoid any band for the cyano group, ${ }^{1} \mathrm{H}$ NMR which displayed peaks at $\delta: 1.13(\mathrm{t}, 3 \mathrm{H}$, $\left.\mathrm{CH}_{3} \mathrm{CH}_{2}-\mathrm{O}, \mathrm{J}=6.0 \mathrm{~Hz}\right), 4.26\left(\mathrm{q}, 2 \mathrm{H},-\mathrm{CH}_{2} \mathrm{O}, \mathrm{J}=\right.$ $6.6 \mathrm{~Hz})$, and MS: $\mathrm{m} / \mathrm{z} 492\left[\mathrm{M}^{+}\right](1.19 \%)$.

Meanwhile, compound 1a was subjected to the reaction with cyanoacetic acid, and/or formamide, to produce cyanoacetamide and pyrazolopyrimidine derivatives 10 and 11 , respectively. When compound $1 \mathrm{~b}$ reacted with triethylorthoformate, ethyl formimidate 12 was produced (Scheme 3).

Formation of compound 10 may take place through the attack of the amino group on the carbonyl of the carboxylic acid followed by elimination of one molecule of water. The IR spectra of 10 revealed the presence of two peaks a 2260 , 2227 which are attributable to two $(\mathrm{CN})$ groups, also, the ${ }^{1} \mathrm{H}-\mathrm{NMR}$ showed peaks at $\delta: 4.50(\mathrm{~s}$, $\left.2 \mathrm{H}, \mathrm{COCH}_{2} \mathrm{CN}\right)$, and $9.65\left(\mathrm{~s}, 1 \mathrm{H}, \mathrm{NH}, \mathrm{D}_{2} \mathrm{O}\right.$ exchangeable) which confirmed the structure.

The IR spectrum of the aminopyrimidine derivative 11 was devoid of $v_{C=N}$ and revealed the appearance of the absorption bands for $\mathrm{NH}_{2}$ group at $3476,3276,3140 \mathrm{~cm}^{-1}$. The mass spectrum of this product showed a peak at $\mathrm{m} / \mathrm{z} 387$ $\left[\mathrm{M}^{+}\right](7.94 \%)$, which approved the structure.

The IR spectrum of compound 12 was devoid of $\mathrm{n}_{\mathrm{NH} 2}$, while its ${ }^{1} \mathrm{H}-\mathrm{NMR}$ displayed peaks at $\delta$ 1.17 ( $\mathrm{t}, 3 \mathrm{H}, \mathrm{CH}_{3} \mathrm{CH}_{2}-\mathrm{O}, \mathrm{J}=6.4 \mathrm{~Hz}$ ), 4.11 (q, $2 \mathrm{H}$, $-\mathrm{CH}_{2} \mathrm{O}, \mathrm{J}=6.8 \mathrm{~Hz}$ ) indicating the presence of the ethyl moiety.

The study was extended to explore the reac- 
Galal H. Sayed, et al.

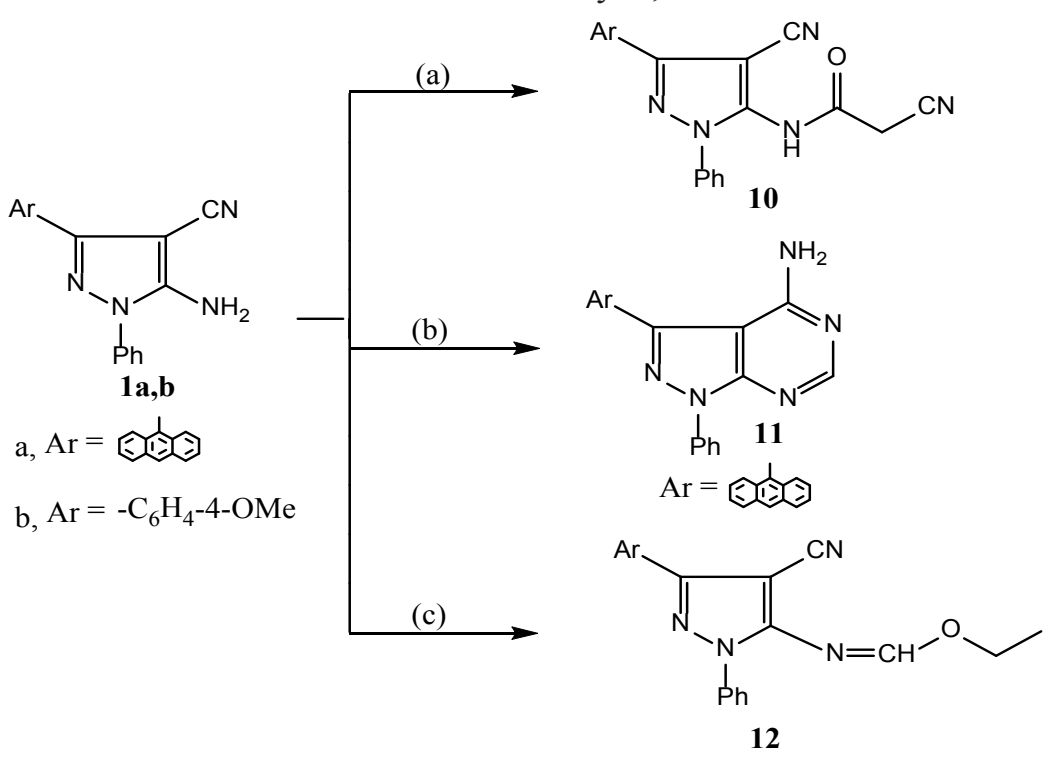

$$
\mathrm{Ar}=-\mathrm{C}_{6} \mathrm{H}_{4}-4-\mathrm{OMe}
$$

Reagents and conditions: a) $\mathrm{CNCH}_{2} \mathrm{COOH}, \mathrm{Ac}_{2} \mathrm{O}$, reflux $1.5 \mathrm{~h}$, b) $\mathrm{HCONH}_{2}$, reflux $6 \mathrm{~h}$, c) $\mathrm{CH}\left(\mathrm{OC}_{2} \mathrm{H}_{5}\right)_{3}, \mathrm{Ac}_{2} \mathrm{O}$, reflux $6 \mathrm{~h}$.

Scheme 3

tivity of the enaminonitriles $1 \mathrm{a}, \mathrm{b}$ towards some carbon and nitrogen nucleophiles. Thus, reaction of $1 \mathrm{a}, \mathrm{b}$ with malononitrile and/or ethyl acetoacetate in the presence of a base afforded the acetonitrile and aminoester derivatives $13 \mathrm{a}, \mathrm{b}$ and 14 , respectively. While treatment of $1 \mathrm{a}, \mathrm{b}$ with hy-

drazine hydrate, thiourea in the presence of sodium ethoxide and/or refluxing with triethyl amine in ethanol, furnished the pyrazolopyrazole ${ }^{[21]}$ and pyrazolopyrimidine $^{[22]}$ derivatives $15 \mathrm{a}, \mathrm{b}, 16$ and 17, respectively (Scheme 4).

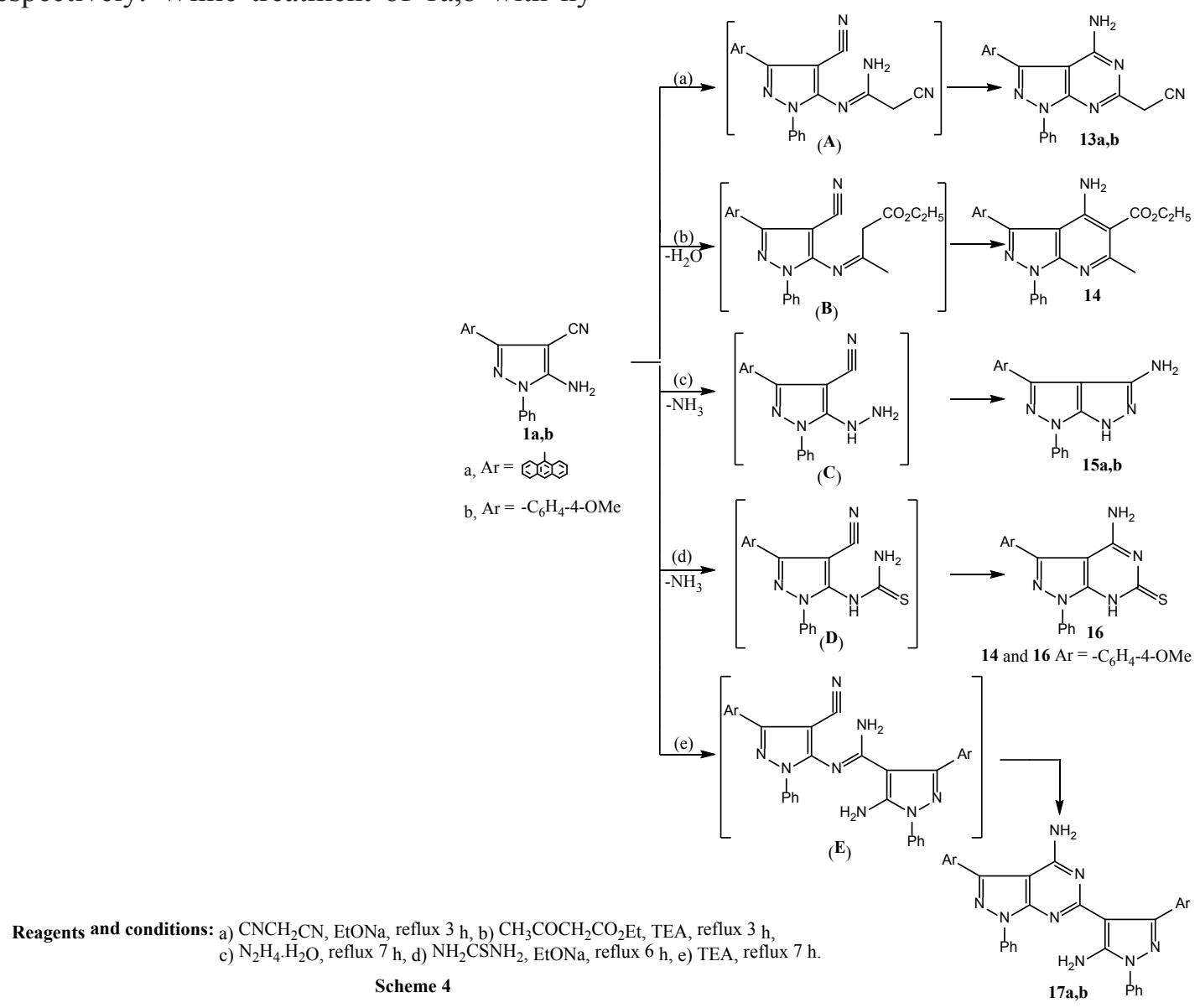


Formation of the acetonitrile derivative 13 may take place through the nucleophilic attack of the amino group on the cyano group of malonitrile to form the intermediate (A) followed by ring closure. The structure of 13 a was supported by its ${ }^{1} \mathrm{H}-\mathrm{NMR}$ which displayed a peak at $\delta 2.16$ $\left(\mathrm{s}, 2 \mathrm{H}, \mathrm{CH}_{2} \mathrm{CN}\right)$ and the mass spectrum which showed $\mathrm{m} / \mathrm{z} 426\left[\mathrm{M}^{+}\right](6.25 \%)$. Also, in compound 14 , the condensation reaction between the amino group and ethyl acetoacetate produced the intermediate (B) which underwent ring closure to form the expected product. The IR of 14 showed the following peaks $3431,3221\left(\mathrm{NH}_{2}\right)$ and 1708 $(\mathrm{C}=\mathrm{O})$, and the ${ }^{1} \mathrm{H}-\mathrm{NMR}$ displayed signals at $\delta$ : 1.19 (t, 3H, $\left.\mathrm{CH}_{3} \mathrm{CH}_{2}-\mathrm{O}, \mathrm{J}=6.2 \mathrm{~Hz}\right), 2.48(\mathrm{~s}, 3 \mathrm{H}$, $\left.\mathrm{CH}_{3}\right), 4.28\left(\mathrm{q}, 2 \mathrm{H},-\mathrm{CH}_{2} \mathrm{O}, \mathrm{J}=6.4 \mathrm{~Hz}\right.$ ) which is in accordance with the structure.

In case of formation of compound 15, hydrazine reacted with the amino group forming the intermediate $(\mathrm{C})$ through the elimination of one molecule of ammonia then ring closure takes place. The structure was indicated from the IR spectra which devoid of $v_{\mathrm{C}=\mathrm{N}}$, and the ${ }^{1} \mathrm{H}-\mathrm{NMR}$ which showed two signals at $\delta 8.63\left(\mathrm{~s}, 2 \mathrm{H}, \mathrm{NH}_{2}\right.$, $\mathrm{D}_{2} \mathrm{O}$ exchangeable) 9.99 (s, $1 \mathrm{H}, \mathrm{NH}, \mathrm{D}_{2} \mathrm{O}$ exchangeable) for compound $15 \mathrm{~b}$. Compound 16 was formed in the same manner through the intermediate (D). But the formation of compound 17 takes place by the reaction of two molecules of compound 1, where the amino group of the first molecule attacks the cyano group of the second molecule producing the intermediate (E) followed by ring closure in the same manner. The structures of the products $17 \mathrm{a}, \mathrm{b}$ get support from the IR spectra which devoid of $v_{\mathrm{C} \equiv \mathrm{N}}$ and the mass spectra which displayed $\mathrm{m} / \mathrm{z} 720\left[\mathrm{M}^{+}\right](16.65 \%)$ and $580\left[\mathrm{M}^{+}\right](1.02 \%)$, respectively.

Reaction of $1 \mathrm{a}, \mathrm{b}$ with sodium azide in the presence of ammonium chloride in dimethylformamide gave the tetrazole derivatives 18a,b. Compounds $18 \mathrm{a}$, b were treated with benzaldehyde, phenacyl bromide/sodium acetate and/or carbon disulfide/pyridine producing the tetrazolopyrimidine, tetrazolodiazepine and tetrazolopyrimidinethione derivatives 19a,b, 20 and 21, respectively (Scheme 5).<smiles>C[Al]C1[Al]C([Al])C1C(N)=O</smiles>

22<smiles>C[13CH2]c1nn(-c2ccccc2)c(N)c1C#N</smiles>

1a,b

a, $\mathrm{Ar}=0 \mathrm{ON}$

$\mathrm{b}, \mathrm{Ar}=-\mathrm{C}_{6} \mathrm{H}_{4}-4-\mathrm{OMe}$<smiles>Nc1c(-c2nnn[nH]2)c(Br)nn1-c1ccccc1</smiles>

18a,b<smiles>[Al]c1nn(-c2ccccc2)c2[nH]c(=S)n3nnnc3c12</smiles>

Reagents and conditions: a) $\mathrm{NaN}_{3}, \mathrm{NH}_{4} \mathrm{Cl}$, reflux $7 \mathrm{~h}$, b) $\mathrm{PhCHO}, \mathrm{HCl}$, reflux 16 h, c) $\mathrm{PhCOCH}_{2} \mathrm{Br}$, AcONa, reflux $10 \mathrm{~h}$, d) $\mathrm{CS}_{2}$, pyridine, reflux $10 \mathrm{~h}$, e) $\mathrm{H}_{2} \mathrm{O}_{2}, \mathrm{NH}_{4} \mathrm{OH}$,stirring $3 \mathrm{~h}$.

Scheme 5 
The absence of the cyano group in the IR spectra and the presence of a signal at $\delta 10.66$ (s, $1 \mathrm{H}, \mathrm{NH}, \mathrm{D}_{2} \mathrm{O}$ exchangeable) in the ${ }^{1} \mathrm{H}-\mathrm{NMR}$ confirmed the proposed structure of product 18 .

The formation of compound 20 may occur through the nucleophilic attack of the NH group (of tetrazole ring) on the carbon atom of the phenacyl bromide via $\mathrm{S}_{\mathrm{N}} 2$ mechanism (with the elimination of $\mathrm{HBr}$ molecule) followed by ring closure through the condensation between the amino group and the carbonyl group.

Finally, when compound 1a was stirred with a mixture of hydrogen peroxide and ammonia solution for three hours at room temperature, a partial hydrolysis for the cyano group takes place and the amide derivative 22 was obtained ${ }^{[23]}$ (Scheme 5). The structure of the product was elucidated from its IR spectrum which devoid of $v_{\mathrm{C}=\mathrm{N}}$ and showed absorption band at 1676 attributable to $\mathrm{C}=\mathrm{O}$ group.

\section{Experimental}

All melting points are uncorrected and were determined on a digital Stuart SMP3 electric melting point apparatus. Infrared (IR) spectra were measured on Perkin-Elmer 293 spectrophotometer $\left(\mathrm{cm}^{-1}\right)$ using $\mathrm{KBr}$ disks. ${ }^{1} \mathrm{H}-\mathrm{NMR}$ spectra were measured on Varian Mercury 400 MHz spectrometer in DMSO- $\mathrm{d}_{6}$ as a solvent using TMS as an internal standard. Chemical shifts

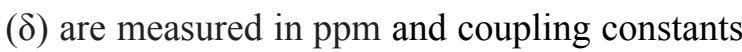
(J) in Hz. The mass spectra were recorded on a GC-2010 Shimadzu Gas chromatography instrument mass spectrometer (70 ev) using the electron ionization technique. Elemental microanalyses were performed on a Perkin-Elmer $\mathrm{CHN}-2400$ analyzer and the microanalyses were within $\pm 0.4 \%$ of the theoretical values. The biological evaluation of the products was carried out at Department of Pharmacology, Faculty of Pharmacy, Mansoura University, Egypt.

5-Amino-3-(anthracen-10-yl)-1-phenyl-1Hpyrazole-4-carbonitrile (1a).

m.p. $146-148^{\circ} \mathrm{C}$. Solvent (EtOH). IR (KBr) $v \mathrm{~cm}^{-1}: 3301\left(\mathrm{NH}_{2}\right), 3076,3049$ (CHar), 2228 $(\mathrm{CN}), 1620(\mathrm{C}=\mathrm{N}), 1598(\mathrm{C}=\mathrm{C}) .{ }^{1} \mathrm{H}-\mathrm{NMR}(400$ MHz, DMSO-d $\left.)_{6}\right) \delta:$ 6.76-8.86 (m, $\left.14 \mathrm{H}, \mathrm{Ar}-\mathrm{H}\right)$, 10.65 (s, $2 \mathrm{H}, \mathrm{NH}_{2}, \mathrm{D}_{2} \mathrm{O}$ exchangeable). MS: $\mathrm{m} / \mathrm{z}$
$360\left[\mathrm{M}^{+}\right](6.75 \%)$. Anal. Calcd for $\mathrm{C}_{24} \mathrm{H}_{16} \mathrm{~N}_{4}$ (360): C, 80.00; H, 4.44; N, 15.55. Found: C, 79.64; H, 4.11; N, 15.90.

N-Acetyl-N-(3-(anthracen-9-yl)-4-cyano1-phenyl-1H-pyrazol-5-yl)acetamide (2).

A mixture of 1a $(0.01 \mathrm{~mol}, 3.6 \mathrm{~g})$ and acetic anhydride $(30 \mathrm{ml})$ was refluxed for $3 \mathrm{~h}$. The reaction mixture was leaved to cool and then pour into ice/water. The solid formed was collected by filtration, washed with water and recrystallized from benzene to produce 2 .

m.p. $198-200{ }^{\circ} \mathrm{C}$. IR (KBr) $v \mathrm{~cm}^{-1}: 3052$ (CHar), 2228(CN), $1683(\mathrm{C}=\mathrm{O}), 1615(\mathrm{C}=\mathrm{N})$. ${ }^{1} \mathrm{H}-\mathrm{NMR}\left(400 \mathrm{MHz}, \mathrm{DMSO}-\mathrm{d}_{6}\right.$ ) $\delta: 2.18$ (s, 6H. $\left.2 \mathrm{COCH}_{3}\right), 7.36-8.89$ (m, $\left.14 \mathrm{H}, \mathrm{Ar}-\mathrm{H}\right)$. MS: $\mathrm{m} / \mathrm{z}$ $444\left[\mathrm{M}^{+}\right](1.00 \%)$. Anal. Calcd for $\mathrm{C}_{28} \mathrm{H}_{20} \mathrm{~N}_{4} \mathrm{O}_{2}$ (444.48): C, 75.66; H, 4.54; N, 12.66. Found: C, 75.30; H, 4.23; N, 12.93 .

3-(Anthracen-9-yl)-6-methyl-1-phenyl-1,5dihydro-4H-pyrazolo[3,4-d]pyrimidin-4-one (3).

A solution of 1a $(0.01 \mathrm{~mol}, 3.6 \mathrm{~g})$ in mix of $10 \mathrm{ml}$ of acetic anhydride and acetic acid (2:1) was refluxed for $8 \mathrm{~h}$. After cooling, the reaction mixture was poured into ice/water, the solid that deposited was filtered off, washed with water, dried and recrystallized from benzene.

m.p. $240-242^{\circ} \mathrm{C}$. IR (KBr) $v \mathrm{~cm}^{-1}: 3455(\mathrm{NH})$, 3052, (CHar), $2229(\mathrm{CN}), 1686(\mathrm{C}=\mathrm{O}), 1613$ $(\mathrm{C}=\mathrm{N}) .{ }^{1} \mathrm{H}-\mathrm{NMR}\left(400 \mathrm{MHz}, \mathrm{DMSO}-\mathrm{d}_{6}\right) \delta: 2.53$ (s, 3H. $\mathrm{CH}_{3}$ ), 7.33-8.63 (m, $\left.14 \mathrm{H}, \mathrm{Ar}-\mathrm{H}\right), 9.11$ (s, $1 \mathrm{H}, \mathrm{NH}, \mathrm{D}_{2} \mathrm{O}$ exchangeable). MS: m/z $402\left[\mathrm{M}^{+}\right]$ (5.01\%). Anal. Calcd for $\mathrm{C}_{26} \mathrm{H}_{18} \mathrm{~N}_{4} \mathrm{O}(402.45)$ : $\mathrm{C}$, 77.59; H, 4.51; N, 13.92. Found: C, 77.98; H, $4.19 ; \mathrm{N}, 14.30$.

N-(3-(anthracen-9-yl)-4-cyano-1-phenyl1H-pyrazol-5-yl)benzamide (4).

To a solution of $1 \mathrm{a}(0.01 \mathrm{~mol}, 3.6 \mathrm{~g})$ in dioxane $(30 \mathrm{ml})$, benzoyl chloride $(0.01 \mathrm{~mole}, 1.4$ $\mathrm{ml})$ and triethylamine $(2 \mathrm{ml})$ were added. The reaction mixture was refluxed for $8 \mathrm{~h}$ then left to cool. The reaction mixture was poured into ice/water, the solid so formed was collected by filtration, washed with water and recrystallized from methanol to produce 4 .

m.p. $236-238^{\circ} \mathrm{C}$. IR $(\mathrm{KBr}) v \mathrm{~cm}^{-1}: 3287(\mathrm{NH})$, 
3054, $3016(\mathrm{CHar}), 1654(\mathrm{C}=\mathrm{O}), 1621(\mathrm{C}=\mathrm{N})$. ${ }^{1} \mathrm{H}-\mathrm{NMR}(400 \mathrm{MHz}$, DMSO-d 6 ) $8:$ 7.49-8.88 (m, $19 \mathrm{H}, \mathrm{Ar}-\mathrm{H}), 9.65$ (s, 1H, NH, $\mathrm{D}_{2} \mathrm{O}$ exchangeable). MS: $\mathrm{m} / \mathrm{z} 464\left[\mathrm{M}^{+}\right](6.75 \%)$. Anal. Calcd for $\mathrm{C}_{31} \mathrm{H}_{20} \mathrm{~N}_{4} \mathrm{O}(464.52)$ : C, 80.15; $\mathrm{H}, 4.34 ; \mathrm{N}$, 11.06. Found: C, 79.86; H, 4.00; N, 12.00 .

3-(Anthracen-9-yl)-5-(1,3-dioxoisoindolin2-yl)-1-phenyl-1H-pyrazole-4-carbonitrile (5).

A mixture of $1 \mathrm{a}(0.01 \mathrm{~mol}, 3.6 \mathrm{~g})$ and phthalic anhydride $(0.01 \mathrm{~mole}, 1.48 \mathrm{~g})$ in acetic acid (30 $\mathrm{ml}$ ) was refluxed for $3 \mathrm{~h}$, left to cool, then poured into ice/water. The solid formed was collected by filtration, washed with water and recrystallized from acetone to give 5 .

m.p. $200-202{ }^{\circ} \mathrm{C}$. IR $(\mathrm{KBr}) v \mathrm{~cm}^{-1}: 3080$, 3053, 3017 (CHar), 2228 (NC), $1698(\mathrm{C}=\mathrm{O})$, $1622(\mathrm{C}=\mathrm{N}) .{ }^{1} \mathrm{H}-\mathrm{NMR}\left(400 \mathrm{MHz}, \mathrm{DMSO}_{-} \mathrm{d}_{6}\right) \delta$ : 7.61-8.89 (m, $18 \mathrm{H}$, Ar-H). MS: m/z $490\left[\mathrm{M}^{+}\right]$ (7.49\%). Anal. Calcd for $\mathrm{C}_{32} \mathrm{H}_{18} \mathrm{~N}_{4} \mathrm{O}_{2}$ (490.51): C, 78.36; H, 3.70; N, 11.42. Found: C, 78.68; H, $3.87 ; \mathrm{N}, 11.06$.

3-(Anthracen-9-yl)-5-((4-methoxybenzylidene)amino)-1-phenyl-1H-pyrazole-4-carbonitrile (6).

To a mixture of 1a $(0.01 \mathrm{~mol}, 3.6 \mathrm{~g})$ and 4-methoxybenzaldehyde (0.01 mole, $1.06 \mathrm{ml})$ in ethanol $(30 \mathrm{ml})$, a few drops of glacial acetic acid was added. The reaction mixture was refluxed for $8 \mathrm{~h}$, left to cool, and then poured into ice/water. The solid so formed was collected by filtration, washed with ethanol and recrystallized from methanol to obtain the Schiff base 6 .

m.p. $208-210^{\circ} \mathrm{C}$. IR $(\mathrm{KBr}) v \mathrm{~cm}^{-1}: 3052,3016$ (CHar), $2228(\mathrm{CN}), 1620(\mathrm{C}=\mathrm{N}) .{ }^{1} \mathrm{H}-\mathrm{NMR}(400$ MHz, DMSO-d $\left.\mathrm{d}_{6}\right) \delta: 3.78\left(\mathrm{~s}, 3 \mathrm{H}, \mathrm{OCH}_{3}\right), 7.62-$ 8.23 (m, $18 \mathrm{H}$, Ar-H), 8.88 (s, 1H, N=CH). MS: $\mathrm{m} / \mathrm{z} 478\left[\mathrm{M}^{+}\right](21.59 \%)$. Anal. Calcd for $\mathrm{C}_{32} \mathrm{H}_{22} \mathrm{~N}_{4} \mathrm{O}$ (478.54): C, 80.32; H, 4.63; N, 11.71 . Found: C, 80.00; H, 4.71; N, 12.02 .

General procedure for the synthesis of compounds $7 \mathrm{a}, \mathrm{b}$.

Compounds 1a,b (0.01 mol), ethanol (30 $\mathrm{ml})$, benzaldehyde and or 4-chlorobenzaldehyde $(0.01$ mole $)$ and $\mathrm{NaOH}(0.72 \mathrm{~g})$ were refluxed for $2 \mathrm{~h}$. The reaction mixture was left to cool and then poured into ice/water, the obtained solid was collected by filtration, washed with water and recrystallized from proper solvent to produce compounds $7 \mathrm{a}, \mathrm{b}$.

3-(Anthracen-9-yl)-4-ethoxy-1,6-diphenyl-1H-pyrazolo[3,4-d]pyrimidine (7a):

m.p. $186-188{ }^{\circ} \mathrm{C}$ (petroleum ether $60-80{ }^{\circ} \mathrm{C} /$ benzene). IR (KBr) $v \mathrm{~cm}^{-1}$ : 3067, 3049 (CHar), $1621(\mathrm{C}=\mathrm{N}) .{ }^{1} \mathrm{H}-\mathrm{NMR}\left(400 \mathrm{MHz}, \mathrm{DMSO}-\mathrm{d}_{6}\right)$ $\delta: 1.13\left(\mathrm{t}, 3 \mathrm{H}, \mathrm{CH}_{3} \mathrm{CH}_{2}-\mathrm{O}, \mathrm{J}=6.0 \mathrm{~Hz}\right), 4.26(\mathrm{q}$, $\left.2 \mathrm{H},-\mathrm{CH}_{2} \mathrm{O}, \mathrm{J}=6.6 \mathrm{~Hz}\right), 6.78-8.77(\mathrm{~m}, 19 \mathrm{H}, \mathrm{Ar}-$ H). MS: $\mathrm{m} / \mathrm{z} 492\left[\mathrm{M}^{+}\right]$(1.19\%). Anal. Calcd for $\mathrm{C}_{33} \mathrm{H}_{24} \mathrm{~N}_{4} \mathrm{O}$ (492.57): C, 80.49; H, 4.91; N, 11.37. Found: C, 80.10; H, 5.12; N, 11.03 .

6-(4-Chloropheny1)-4-ethoxy-3-(4methoxyphenyl)-1-phenyl-1H-pyrazolo[3,4-d] pyrimidine $(7 b)$ :

m.p. above $300^{\circ} \mathrm{C}(\mathrm{EtOH})$. IR ( $\left.\mathrm{KBr}\right) v \mathrm{~cm}^{-1}$ : 3073, 3010 (CHar). MS: m/z 456 [M+] (5.67\%). Anal. Calcd for $\mathrm{C}_{26} \mathrm{H}_{21} \mathrm{ClN}_{4} \mathrm{O}_{2}$ (456.92): C, 68.43; H, 4.63; Cl, 7.76; N, 12.26. Found: C, $68.09 ; \mathrm{H}, 4.81 ; \mathrm{Cl}, 8.10 ; \mathrm{N}, 11.93$.

General procedure for the synthesis of compounds $8 \mathrm{a}, \mathrm{b}$.

To compounds $1 \mathrm{a}, \mathrm{b}(0.01 \mathrm{~mol})$, carbon disulfide $(15 \mathrm{ml})$ was added dropwise at room temperature with stirring for $30 \mathrm{~min}$. The reaction mixture was refluxed for $2 \mathrm{~h}$, then left to cool. The solid that separated out was collected by filtration and recrystallized from suitable solvent to give $8 \mathrm{a}, \mathrm{b}$.

3-(Anthracen-9-yl)-4-imino-1-phenyl-4,7dihydropyrazolo[3,4-d][1,3]thiazine- $6(1 \mathrm{H})$-thione (8a).

m.p. $204-206^{\circ} \mathrm{C}$ (benzene). IR $(\mathrm{KBr}) v \mathrm{~cm}^{-}$ 1: 3434, $3300(\mathrm{NH}), 3075,3048$, (CHar), 1621 $(\mathrm{C}=\mathrm{N}) .{ }^{1} \mathrm{H}-\mathrm{NMR}\left(400 \mathrm{MHz}, \mathrm{DMSO}-\mathrm{d}_{6}\right) \delta: 6.77-$ 8.76 (m, 14 H, Ar-H), 9.10 (s, 1H, NH, $\mathrm{D}_{2} \mathrm{O}$ exchangeable). $10.65\left(\mathrm{~s}, 1 \mathrm{H}, \mathrm{NH}, \mathrm{D}_{2} \mathrm{O}\right.$ exchangeable). MS: $\mathrm{m} / \mathrm{z} 436\left[\mathrm{M}^{+}\right]$(11.09\%). Anal. Calcd for $\mathrm{C}_{25} \mathrm{H}_{16} \mathrm{~N}_{4} \mathrm{~S}_{2}$ (436.55): $\mathrm{C}, 68.78 ; \mathrm{H}, 3.69 ; \mathrm{N}$, 12.83; S, 14.66. Found: C, 69.10; H, 3.86; N, 13.16; S, 15.01 .

4-Imino-3-(4-methoxyphenyl)-1-phenyl-4,7dihydropyrazolo[3,4-d][1,3] thiazine- $6(1 \mathrm{H})$-thione (8b). 
m.p. $120-122^{\circ} \mathrm{C}(\mathrm{EtOH})$. IR $(\mathrm{KBr}) \vee \mathrm{cm}^{-1}$ : 3425, $3313(\mathrm{NH}), 3045,3020$, (CHar), 1596 $(\mathrm{C}=\mathrm{N}) . \mathrm{MS}: \mathrm{m} / \mathrm{z} 366\left[\mathrm{M}^{+}\right](7.22 \%)$. Anal. Calcd for $\mathrm{C}_{18} \mathrm{H}_{14} \mathrm{~N}_{4} \mathrm{OS}_{2}$ (366.46): C, 58.99; $\mathrm{H}, 3.85 ; \mathrm{N}$, 15.29 ; S, 17.50. Found: C, 59.33; H, 4.04; N, $15.03 ; \mathrm{S}, 17.81$.

General procedure for the synthesis of compounds $9 a, b$.

To a mixture of $1 \mathrm{a}, \mathrm{b}(0.01 \mathrm{~mol})$ and potassium hydroxide $(0.2 \mathrm{~g})$ in ethanol $(30 \mathrm{ml})$, carbon disulfide $(3.5 \mathrm{ml})$ was added. The reaction mixture was refluxed for $12 \mathrm{~h}$, left to cool, then poured into ice/water. The solid formed was collected by filtration, washed with ethanol and recrystallized from proper solvent to give compounds $9 \mathrm{a}, \mathrm{b}$.

3 -(Anthracen-9-yl)-1-pheny1-1,7-dihydro-4H-pyrazolo[3,4-d]pyrimidine- $4,6(5 \mathrm{H})$ dithione (9a).

m.p. $210-212^{\circ} \mathrm{C}(\mathrm{MeOH})$. IR $(\mathrm{KBr}) \vee \mathrm{cm}^{-}$ 1: $3264(\mathrm{NH})$, 3049, (CHar), $1619(\mathrm{C}=\mathrm{N}) .{ }^{1} \mathrm{H}-$ NMR (400 MHz, DMSO-d $\left.{ }_{6}\right) \delta: 6.70-8.97$ (m, 14 $\mathrm{H}, \mathrm{Ar}-\mathrm{H}), 9.12$ (s, 1H, NH, $\mathrm{D}_{2} \mathrm{O}$ exchangeable), 10.61 (s, $1 \mathrm{H}, \mathrm{NH}, \mathrm{D}_{2} \mathrm{O}$ exchangeable). MS: m/z $436\left[\mathrm{M}^{+}\right](11.98 \%)$. Anal. Calcd for $\mathrm{C}_{25} \mathrm{H}_{16} \mathrm{~N}_{4} \mathrm{~S}_{2}$ (436.55): C, 68.78; H, 3.69; N, 12.83; S, 14.69. Found: C, 68.44; H, 3.91; N, 12.46; S, 14.99 .

3-(4-Methoxyphenyl)-1-phenyl-1,7-dihydro-4H-pyrazolo[3,4-d]pyrimidine- $4,6(5 \mathrm{H})$ dithione (9b).

m.p. $124-126{ }^{\circ} \mathrm{C}(\mathrm{EtOH}) . \mathrm{IR}(\mathrm{KBr}) \vee \mathrm{cm}^{-}$ 1: 3428, $3313(\mathrm{NH}), 3046,3021$, (CHar), 1620 $(\mathrm{C}=\mathrm{N})$. MS: $\mathrm{m} / \mathrm{z} 366\left[\mathrm{M}^{+}\right](2.18 \%)$. Anal. Calcd for $\mathrm{C}_{18} \mathrm{H}_{14} \mathrm{~N}_{4} \mathrm{OS}_{2}$ (366.46): C, 59.02; H, 3.82; N, 15.30; S, 17.49. Found: C, 59.38; H, 3.50; N, 15.67; S, 17.15 .

N-(3-(Anthracen-9-yl)-4-cyano-1-phenyl1H-pyrazol-5-yl)-2-cyanoacetamide (10).

A mixture of $1 \mathrm{a}(0.01 \mathrm{~mol}, 3.6 \mathrm{~g})$ and cyanoacetic acid $(0.01 \mathrm{~mol}, 1 \mathrm{~g})$ in acetic anhydride $(30$ $\mathrm{ml}$ ) was refluxed for $1.5 \mathrm{~h}$, left to cool and then poured into ice/ water with vigorous stirring. The solid that separated out was collected by filtration, washed with water and recrystallized from ethanol to give compound 10 .

m.p. $180-182^{\circ} \mathrm{C}$. IR (KBr) $v \mathrm{~cm}^{-1}: 3184(\mathrm{NH})$,
3051, 30.16 (CHar), 2260, $2227(\mathrm{CN}), 1686$ $(\mathrm{C}=\mathrm{O}), 1620(\mathrm{C}=\mathrm{N}) .{ }^{1} \mathrm{H}-\mathrm{NMR}(400 \mathrm{MHz}, \mathrm{DM}-$ $\left.\mathrm{SO}-\mathrm{d}_{6}\right) \delta: 4.50\left(\mathrm{~s}, 2 \mathrm{H}, \mathrm{COCH}_{2} \mathrm{CN}\right), 7.53-8.88(\mathrm{~m}$, $14 \mathrm{H}, \mathrm{Ar}-\mathrm{H}), 9.65$ (s, 1H, NH, $\mathrm{D}_{2} \mathrm{O}$ exchangeable). MS: m/z $427\left[\mathrm{M}^{+}\right]$(4.59\%). Anal. Calcd for $\mathrm{C}_{27} \mathrm{H}_{17} \mathrm{~N}_{5} \mathrm{O}$ (427.46): C, 75.86; H, 4.01; N, 16.38. Found: C, 76.20; H, 4.22; N, 16.76 .

3 - (Anthracen-9-yl)-1-phenyl-1Hpyrazolo[3,4-d]pyrimidin-4-amine (11).

A solution of $1 \mathrm{a}(0.01 \mathrm{~mol}, 3.6 \mathrm{~g})$ and formamide $(30 \mathrm{ml})$ was refluxed for $4 \mathrm{~h}$, left to cool and then poured into ice/water. The solid so formed was collected by filtration, washed with water and recrystallized from methanol to produce the pyrazolopyrimidine derivative 11 .

m.p. $234-236{ }^{\circ} \mathrm{C}$. IR (KBr) $v \mathrm{~cm}^{-1}: 3276$, $3140\left(\mathrm{NH}_{2}\right), 3080,3050$, (CHar), $1640(\mathrm{C}=\mathrm{N})$. ${ }^{1} \mathrm{H}-\mathrm{NMR}\left(400 \mathrm{MHz}, \mathrm{DMSO}-\mathrm{d}_{6}\right) \delta: 5.32(\mathrm{~s}, 2 \mathrm{H}$, $\mathrm{NH}_{2}, \quad \mathrm{D}_{2} \mathrm{O}$ exchangeable), 7.51-8.72 (m, 15 $\mathrm{H}$, Ar-H+ pyrimidine-H). MS: m/z $387\left[\mathrm{M}^{+}\right]$ (7.94\%). Anal. Calcd for $\mathrm{C}_{25} \mathrm{H}_{17} \mathrm{~N}_{5}$ (387.44): C, 77.50; H, 4.42; N, 18.08. Found: C, 77.24; H, $4.55 ; \mathrm{N}, 17.79$.

Ethyl N-(4-cyano-3-(4-methoxyphenyl)1-phenyl-1H-pyrazol-5-yl)formimidate (12).

A mixture of compound $1 \mathrm{~b}(0.01 \mathrm{~mol}, 2.9$ $\mathrm{g})$, triethyl orthoformate $(3 \mathrm{ml})$ and acetic anhydride $(3 \mathrm{ml})$ was refluxed for $6 \mathrm{~h}$. The solid that precipitated out upon cooling was collected by filtration, washed with ethanol and recrystallized from ethanol to give the formimidate derivative 12 .

m.p. $130-132{ }^{\circ} \mathrm{C}$. IR $(\mathrm{KBr}) \vee \mathrm{cm}^{-1}$ : 3072, 3028, (CHar), $2222(\mathrm{CN}), 1605(\mathrm{C}=\mathrm{N}) .{ }^{1} \mathrm{H}-\mathrm{NMR}$ (400 $\mathrm{MHz}$, DMSO-d 6 ) $\delta: 1.17$ (t, 3H, $\mathrm{CH}_{3} \mathrm{CH}_{2}-\mathrm{O}, \mathrm{J}=$ $6.4 \mathrm{~Hz}), 3.88\left(\mathrm{~s}, 3 \mathrm{H}, \mathrm{OCH}_{3}\right), 4.11\left(\mathrm{q}, 2 \mathrm{H},-\mathrm{CH}_{2} \mathrm{O}\right.$, $\mathrm{J}=6.8 \mathrm{~Hz}), 7.16-7.99(\mathrm{~m}, 9 \mathrm{H}, \operatorname{Ar}-\mathrm{H}), 8.37(\mathrm{~s}$, $1 \mathrm{H}, \mathrm{N}=\mathrm{CH})$. MS: m/z $346\left[\mathrm{M}^{+}\right](12.02 \%)$. Anal. Calcd for $\mathrm{C}_{20} \mathrm{H}_{18} \mathrm{~N}_{4} \mathrm{O}_{2}$ (346.38): C, 69.35; $\mathrm{H}$, 5.24; N, 16.17. Found: C, 69.01; H, 4.90; N, 15.81 .

General procedure for the synthesis of compounds 13a,b.

A mixture of compounds $1 \mathrm{a}, \mathrm{b}(0.01 \mathrm{~mol})$, malononitrile $(0.01 \mathrm{~mol}, 0.66 \mathrm{~g})$.and sodium ethoxide ( $0.23 \mathrm{~g}$ in $20 \mathrm{ml}$ ethanol) was refluxed 
for $7 \mathrm{~h}$. The reaction mixture was left to cool. The solid so formed was collected by filtration, washed with ethanol and recrystallized from ethanol to produce compounds 13a,b.

2-(4-amino-3-(anthracen-9-yl)-1-phenyl1H-pyrazolo[3,4-d]pyrimidin-6-yl)acetonitrile (13a).

m.p. $>300{ }^{\circ} \mathrm{C}$. IR $(\mathrm{KBr}) \vee \mathrm{cm}^{-1}: 3302,3267$ $\left(\mathrm{NH}_{2}\right), 3051$, (CHar), $2256(\mathrm{CN}), 1646(\mathrm{C}=\mathrm{N})$. ${ }^{1} \mathrm{H}-\mathrm{NMR}\left(400 \mathrm{MHz}, \mathrm{DMSO}_{\mathrm{d}}\right) \delta: 2.16(\mathrm{~s}, 2 \mathrm{H}$, $\mathrm{CH}_{2} \mathrm{CN}$ ), 6.78-8.77 (m, $\left.14 \mathrm{H}, \mathrm{Ar}-\mathrm{H}\right), 10.69$ (s, $2 \mathrm{H}, \mathrm{NH}_{2}, \mathrm{D}_{2} \mathrm{O}$ exchangeable). MS: $\mathrm{m} / \mathrm{z} 426\left[\mathrm{M}^{+}\right]$ (6.25\%). Anal. Calcd for $\mathrm{C}_{27} \mathrm{H}_{18} \mathrm{~N}_{6}$ (426.47): $\mathrm{C}$, 76.04; H, 4.25; N, 19.71. Found: C, 76.40; H, $4.00 ; \mathrm{N}, 20.01$.

2-(4-Amino-3-(4-methoxyphenyl)-1-phenyl-1H-pyrazolo[3,4-d]pyrimidin-6-yl)acetonitrile (13b).

m.p. $190-192^{\circ} \mathrm{C}$. IR $(\mathrm{KBr}) v \mathrm{~cm}^{-1}: 3420,3314$ $\left(\mathrm{NH}_{2}\right), 3042$, (CHar), $2254(\mathrm{CN}), 1610(\mathrm{C}=\mathrm{N})$. MS: m/z $356\left[\mathrm{M}^{+}\right]$(4.44\%). Anal. Calcd for $\mathrm{C}_{20} \mathrm{H}_{16} \mathrm{~N}_{6} \mathrm{O}$ (356.38): C, 67.40; H, 4.53; N, 23.58. Found: C, 67.78; H, 4.26; N, 23.96.

Ethyl-4-amino-3-(4-methoxyphenyl)6-methyl-1-phenyl-1H-pyrazolo[3,4-b]pyridine5-carboxylate (14).

A mixture of compound $1 \mathrm{~b}(0.01 \mathrm{~mol}, 2.9 \mathrm{~g})$, ethyl acetoacetate $(0.01 \mathrm{~mol}, 1.13 \mathrm{ml})$ and few drops of triethyl amine in acetic acid $(30 \mathrm{ml})$ was refluxed for $3 \mathrm{~h}$. After cooling, the reaction mixture was poured into ice $/ \mathrm{HCl}$. The solid that separated out was collected by filtration, washed with water and recrystallized from ethanol to give the pure ester 14 .

m.p. $122-124{ }^{\circ} \mathrm{C}$. IR $(\mathrm{KBr}) \vee \mathrm{cm}^{-1}: 3431,3221$ $\left(\mathrm{NH}_{2}\right), 3030,(\mathrm{CHar}), 1708(\mathrm{C}=\mathrm{O}), 1608(\mathrm{C}=\mathrm{N})$. ${ }^{1} \mathrm{H}-\mathrm{NMR}(400 \mathrm{MHz}$, DMSO-d $)$ ) $\delta: 1.19$ (t, 3H, $\left.\mathrm{CH}_{3} \mathrm{CH}_{2}-\mathrm{O}, \mathrm{J}=6.2 \mathrm{~Hz}\right), 2.48\left(\mathrm{~s}, 3 \mathrm{H}, \mathrm{CH}_{3}\right) 3.77$ $\left(\mathrm{s}, 3 \mathrm{H}, \mathrm{CH}_{3} \mathrm{O}\right), 4.28\left(\mathrm{q}, 2 \mathrm{H},-\mathrm{CH}_{2} \mathrm{O}, \mathrm{J}=6.4 \mathrm{~Hz}\right)$, 6.82-7.94 (m, $9 \mathrm{H}, \operatorname{Ar}-\mathrm{H}), 9.87$ (s, 2H, $\mathrm{NH}_{2}$, $\mathrm{D}_{2} \mathrm{O}$ exchangeable). MS: $\mathrm{m} / \mathrm{z} 402\left[\mathrm{M}^{+}\right](2.76 \%)$. Anal. Calcd for $\mathrm{C}_{23} \mathrm{H}_{22} \mathrm{~N}_{4} \mathrm{O}_{3}$ (402.45): C, 68.64; H, 5.51; N, 13.93. Found: C, 69.01; H, 5.22; N, 14.14.

General procedure for the synthesis of compounds $15 \mathrm{a}, \mathrm{b}$.
A mixture of 1a,b $(0.01 \mathrm{~mol})$ and hydrazine hydrate $(0.02 \mathrm{~mol}, 1 \mathrm{ml})$ in $30 \mathrm{ml}$ ethanol was refluxed for $3 \mathrm{~h}$. The reaction mixture was left to cool. The solid so formed was collected by filtration, washed with ethanol and recrystallized from ethanol to give the pyrazolopyrazole derivatives $15 \mathrm{a}, \mathrm{b}$.

4 - (Anthracen-9-y1)-6-pheny1-1,6dihydropyrazolo[3,4-c]pyrazol-3-amine (15a).

m.p. $210-212{ }^{\circ} \mathrm{C}$. IR (KBr) $\vee \mathrm{cm}^{-1}: 3300$ $\left(\mathrm{NH}_{2}\right), 3076,3049$, (CHar), $1621(\mathrm{C}=\mathrm{N}) . \mathrm{MS}$ : $\mathrm{m} / \mathrm{z} 375\left[\mathrm{M}^{+}\right]$(5.55) Anal. Calcd for $\mathrm{C}_{24} \mathrm{H}_{17} \mathrm{~N}_{5}$ (375.43): C, 76.78; H, 4.56; N, 18.65. Found: C, 77.13; H, 4.33; N, 19.00 .

4-(4-Methoxyphenyl)-6-pheny1-1,6dihydropyrazolo[3,4-c]pyrazol-3-amine (15b).

m.p. $156-158{ }^{\circ} \mathrm{C}$. IR (KBr) $v \mathrm{~cm}^{-1}: 3428$ br. $\left(\mathrm{NH}_{2}, \mathrm{NH}\right)$, 3037, 3009 (CHar), $1623(\mathrm{C}=\mathrm{N})$. $\left.{ }^{1} \mathrm{H}-\mathrm{NMR}(400 \mathrm{MHz}, \text { DMSO-d })_{6}\right) \delta: 3.83$ (s, 3H, $\mathrm{CH}_{3} \mathrm{O}$ ), 7.04-7.83 (m, $\left.9 \mathrm{H}, \mathrm{Ar}-\mathrm{H}\right), 8.63$ (s, 2H, $\mathrm{NH}_{2}, \mathrm{D}_{2} \mathrm{O}$ exchangeable) $9.99\left(\mathrm{~s}, 1 \mathrm{H}, \mathrm{NH}, \mathrm{D}_{2} \mathrm{O}\right.$ exchangeable). MS: m/z $305\left[\mathrm{M}^{+}\right]$(5.03\%). Anal. Calcd for $\mathrm{C}_{17} \mathrm{H}_{15} \mathrm{~N}_{5} \mathrm{O}$ (305.33): C, 66.87; H, 4.95; N, 22.94. Found: C, 67.22; H, 5.20; N, 23.29 .

4-Amino-3-(4-methoxyphenyl)-1-phenyl-1,7-dihydro-6H-pyrazolo[3,4-d]pyrimidine6-thione (16).

To a mixture of compound $1 \mathrm{~b}(0.01 \mathrm{~mol}, 2.9$ $\mathrm{g})$ and thiourea $(0.01 \mathrm{~mol}, 0.72 \mathrm{~g})$, sodium ethoxide $(0.23 \mathrm{~g}$ in $20 \mathrm{ml}$ ethanol) was added and the reaction mixture was refluxed for $7 \mathrm{~h}$. The solid that separated out after cooling was collected by filtration, washed with ethanol and recrystallized from ethanol to furnish compound 16 .

m.p. 186-188 ${ }^{\circ} \mathrm{C}$. IR (KBr) $\vee \mathrm{cm}^{-1}: 3313$, $3283\left(\mathrm{NH}_{2}, \mathrm{NH}\right), 3049(\mathrm{CHar}), 1600(\mathrm{C}=\mathrm{N})$. ${ }^{1} \mathrm{H}-\mathrm{NMR}\left(400 \mathrm{MHz}, \mathrm{DMSO}-\mathrm{d}_{6}\right) \delta: 3.78(\mathrm{~s}, 3 \mathrm{H}$, $\left.\mathrm{CH}_{3} \mathrm{O}\right), 6.69-7.82$ (m, $\left.9 \mathrm{H}, \mathrm{Ar}-\mathrm{H}\right), 9.30$ (s, $1 \mathrm{H}$, $\mathrm{NH}, \mathrm{D}_{2} \mathrm{O}$ exchangeable) $10.11\left(\mathrm{~s}, 2 \mathrm{H}, \mathrm{NH}_{2}, \mathrm{D}_{2} \mathrm{O}\right.$ exchangeable). MS: m/z $349\left[\mathrm{M}^{+}\right](10.13 \%)$. Anal. Calcd for $\mathrm{C}_{18} \mathrm{H}_{15} \mathrm{~N}_{5} \mathrm{OS}$ (349.41): C, 61.87; $\mathrm{H}, 4.33$; N, 20.04; S, 9.18. Found: C, 62.24; H, $4.08 ; \mathrm{N}, 19.70 ; \mathrm{S}, 8.88$.

General procedure for the synthesis of compounds $17 \mathrm{a}, \mathrm{b}$. 
A mixture of compounds $1 \mathrm{a}, \mathrm{b}(0.02 \mathrm{~mol})$ and triethylamine $(2 \mathrm{ml})$ was dissolved in $30 \mathrm{ml}$ ethanol and refluxed for $7 \mathrm{~h}$. The reaction mixture was left to cool. The solid so formed was collected by filtration, washed with ethanol and recrystallized from ethanol to give $17 \mathrm{a}, \mathrm{b}$.

6-(5-Amino-3-(anthracen-9-yl)-1-phenyl1H-pyrazol-4-yl)-3-(anthracen-9-yl)-1-phenyl1H-pyrazolo[3,4-d]pyrimidin-4-amine (17a).

m.p. $212-214^{\circ} \mathrm{C}$. IR $(\mathrm{KBr}) \vee \mathrm{cm}^{-1}: 3301\left(\mathrm{NH}_{2}\right)$, 3076, 3048 (CHar), $1621(\mathrm{C}=\mathrm{N}) .{ }^{1} \mathrm{H}-\mathrm{NMR}$ (400 MHz, DMSO-d $)$ $\delta:$ 6.78-8.77 (m, $28 \mathrm{H}, \mathrm{Ar}-\mathrm{H})$, $9.10\left(\mathrm{~s}, 2 \mathrm{H}, \mathrm{NH}_{2}, \mathrm{D}_{2} \mathrm{O}\right.$ exchangeable) $10.65(\mathrm{~s}$, $2 \mathrm{H}, \mathrm{NH}_{2}, \mathrm{D}_{2} \mathrm{O}$ exchangeable). MS: m/z $720\left[\mathrm{M}^{+}\right]$ (16.65\%). Anal. Calcd for $\mathrm{C}_{48} \mathrm{H}_{32} \mathrm{~N}_{8}$ (720.82): $\mathrm{C}$, 79.98; H, 4.43; N, 15.55. Found: C, 79.70; H, 4.14; N, 15.90 .

6-(5-Amino-3-(4-methoxyphenyl)-1-phenyl-1H-pyrazol-4-yl)-3-(4-methoxyphenyl)-1phenyl-1H-pyrazolo[3,4-d]pyrimidin-4-amine (17b).

m.p. $166-168^{\circ} \mathrm{C}$. IR $(\mathrm{KBr}) v \mathrm{~cm}^{-1}: 3424,3313$ $\left(\mathrm{NH}_{2}\right), 3045,3020(\mathrm{CHar}), 1596(\mathrm{C}=\mathrm{N}) . \mathrm{MS}: \mathrm{m} / \mathrm{z}$ $580\left[\mathrm{M}^{+}\right](1.02 \%)$. Anal. Calcd for $\mathrm{C}_{34} \mathrm{H}_{28} \mathrm{~N}_{8} \mathrm{O}_{2}$ (580.64): C, 70.33; H, 4.86; N, 19.30. Found: C, $70.68 ; \mathrm{H}, 5.12 ; \mathrm{N}, 18.98$.

General procedure for the synthesis of compounds 18a,b.

Sodium azide $(0.01 \mathrm{~mol}, 0.65 \mathrm{~g})$ and ammonium chloride $(0.01 \mathrm{~mol}, 0.53 \mathrm{~g})$ were added to a solution of compounds 1a,b (0.005 mol) in DMF $(15 \mathrm{ml})$. The reaction mixture was refluxed for 7 $\mathrm{h}$, left to cool at room temperature, then poured into ice/water. The solid that deposited was collected by filtration, washed with water and recrystallized from petroleum ether $80-100{ }^{\circ} \mathrm{C}$ to produce pure solids of compounds 18a,b.

3-(Anthracen-9-yl)-1-phenyl-4-(1H-tetrazol5-yl)-1H-pyrazol-5-amine (18a).

m.p. $206-208^{\circ} \mathrm{C}$. IR (KBr) $v \mathrm{~cm}^{-1}: 3300,3265$ $\left(\mathrm{NH}_{2}, \mathrm{NH}\right), 3075,3049$ (CHar), $1620(\mathrm{C}=\mathrm{N}) .{ }^{1} \mathrm{H}-$ NMR (400 MHz, DMSO-d $)$ ) 6: 6.77-8.97 (m, 14 $\mathrm{H}, \mathrm{Ar}-\mathrm{H}), 9.09$ (s, 2H, $\mathrm{NH}_{2}, \mathrm{D}_{2} \mathrm{O}$ exchangeable) 10.66 (s, $1 \mathrm{H}, \mathrm{NH}, \mathrm{D}_{2} \mathrm{O}$ exchangeable). MS: m/z $403\left[\mathrm{M}^{+}\right](4.84 \%)$. Anal. Calcd for $\mathrm{C}_{24} \mathrm{H}_{17} \mathrm{~N}_{7}$ (403.44): C, 71.45; H, 4.25; N, 24.30. Found: C,
71.75; H, 3.99; N, 23.98.

3-(4-Methoxyphenyl)-1-phenyl-4-(1H-tetrazol-5-yl)-1H-pyrazol-5-amine (18b).

m.p. $118-120^{\circ} \mathrm{C}$. IR $(\mathrm{KBr}) v \mathrm{~cm}^{-1}: 3427,3313$ $\left(\mathrm{NH}_{2}, \mathrm{NH}\right), 3046,3020$ (CHar), $1597(\mathrm{C}=\mathrm{N})$. MS: $\mathrm{m} / \mathrm{z} 333\left[\mathrm{M}^{+}\right]$(1.28\%). Anal. Calcd for $\mathrm{C}_{17} \mathrm{H}_{15} \mathrm{~N}_{7} \mathrm{O}$ (333.35): C, 61.25; H, 4.54; N, 29.41. Found: C, 60.94; H, 4.76; N, 29.08.

General procedure for the synthesis of compounds 19a,b.

To a mixture of compounds 18a,b (0.005 mol) and benzaldehyde $(0.005 \mathrm{~mol}, 0.5 \mathrm{ml})$ in methanol $(25 \mathrm{ml}), \mathrm{HCl}(1.5 \mathrm{ml})$ was added. The reaction mixture was refluxed for $16 \mathrm{~h}$, left to cool, and then pour into cold solution of sodium carbonate. The solid that separated out was collected by filtration, washed with water several times and recrystallized from ethanol to give compounds $19 \mathrm{a}, \mathrm{b}$, respectively.

9-(Anthracen-9-yl)-5,7-diphenyl-6,7-dihydro-5H-pyrazolo[4,3-e]tetrazolo[1,5-c]pyrimidine (19a).

m.p. $228-230^{\circ} \mathrm{C}$. IR $(\mathrm{KBr}) v \mathrm{~cm}^{-1}: 3266(\mathrm{NH})$, 3048, 3024 (CHar), $1601(\mathrm{C}=\mathrm{N}) .{ }^{1} \mathrm{H}-\mathrm{NMR}(400$ $\mathrm{MHz}$, DMSO-d $\left.)_{6}\right) \delta: 5.45$ (s, 1H, CH-pyrimidine), 6.71-8.97 (m, $19 \mathrm{H}, \mathrm{Ar}-\mathrm{H}), 10.62$ (s, 1H, $\mathrm{NH}, \mathrm{D}_{2} \mathrm{O}$ exchangeable). MS: $\mathrm{m} / \mathrm{z} 491\left[\mathrm{M}^{+}\right]$ (1.81\%). Anal. Calcd for $\mathrm{C}_{31} \mathrm{H}_{21} \mathrm{~N}_{7}$ (491.55): $\mathrm{C}$, 75.75; H, 4.31; N, 19.95. Found: C, 76.04; H, $4.00 ; \mathrm{N}, 20.30$.

9-(4-Methoxyphenyl)-5,7-diphenyl-6,7-dihydro-5H-pyrazolo[4,3-e]tetrazolo[1,5-c]pyrimidine (19b).

m.p. $162-164{ }^{\circ} \mathrm{C}$. IR $(\mathrm{KBr}) \vee \mathrm{cm}^{-1}: 3308$ (NH), 3055, 3025 (CHar), $1608(\mathrm{C}=\mathrm{N}) . \mathrm{MS}: \mathrm{m} / \mathrm{z}$ $421\left[\mathrm{M}^{+}\right](11.88 \%)$. Anal. Calcd for $\mathrm{C}_{24} \mathrm{H}_{19} \mathrm{~N}_{7} \mathrm{O}$ (421.45): C, 68.40; H, 4.54; N, 23.26. Found: C, 68.78; H, 4.80; N, 22.92.

10-(4-Methoxyphenyl)-6,8-diphenyl-5,8dihydropyrazolo[4,3-f]tetrazolo[1,5-d][1,4]diazepine (20).

A mixture of $18 \mathrm{~b}(0.005 \mathrm{~mol}, 1.67 \mathrm{~g})$, phenacyl bromide $(0.005 \mathrm{~mol}, 1.125 \mathrm{~g})$ and sodium acetate $(1.85 \mathrm{~g})$ was refluxed in ethanol $(25 \mathrm{ml})$ for $10 \mathrm{~h}$. The reaction mixture was left to cool, then 
poured into ice/water. The solid so formed was collected by filtration, washed with water and recrystallized from methanol to obtain the pure diazipine derivative 20 .

m.p. $>300^{\circ} \mathrm{C}$. IR $(\mathrm{KBr}) \vee \mathrm{cm}^{-1}: 3058,3025$ (CHar), $1600(\mathrm{C}=\mathrm{N}) .{ }^{1} \mathrm{H}-\mathrm{NMR}(400 \mathrm{MHz}, \mathrm{DM}-$ SO-d $\left.)_{6}\right) \delta: 3.74\left(\mathrm{~s}, 3 \mathrm{H}, \mathrm{OCH}_{3}\right), 4.21\left(\mathrm{~s}, 2 \mathrm{H}, \mathrm{CH}_{2}-\right.$ diazipine), 6.71-8.97 (m, $14 \mathrm{H}, \mathrm{Ar}-\mathrm{H})$. MS: m/z $433\left[\mathrm{M}^{+}\right](6.09 \%)$. Anal. Calcd for $\mathrm{C}_{25} \mathrm{H}_{19} \mathrm{~N}_{7} \mathrm{O}$ (433.46): C, 69.27; H, 4.42; N, 22.62. Found: C, 68.92; H, 4.70; N, 23.00.

9-(Anthracen-9-yl)-7-pheny1-6,7-dihydro-5H-pyrazolo[4,3-e]tetrazolo[1,5-c]pyrimidine-5-thione (21).

A mixture of $18 \mathrm{a}(0.005 \mathrm{~mol}, 2.17 \mathrm{~g})$, carbon disulfide $(0.37 \mathrm{~g})$ in pyridine $(10 \mathrm{ml})$ was refluxed for $10 \mathrm{~h}$. The reaction mixture was left to cool, and then poured into ice/ $\mathrm{HCl}$. The solid that separated out was collected by filtration, washed with water and recrystallized from methanol to produce 21 .

m.p. $188-190^{\circ} \mathrm{C}$. IR $(\mathrm{KBr}) v \mathrm{~cm}^{-1}: 3300(\mathrm{NH})$, 3075, 3048 (CHar), $1621(\mathrm{C}=\mathrm{N}) .{ }^{1} \mathrm{H}-\mathrm{NMR}(400$ MHz, DMSO-d $\left.{ }_{6}\right) \delta: 6.71-8.96$ (m, $\left.14 \mathrm{H}, \mathrm{Ar}-\mathrm{H}\right)$, 10.65 (s, $1 \mathrm{H}, \mathrm{NH}, \mathrm{D}_{2} \mathrm{O}$ exchangeable). $\mathrm{MS}: \mathrm{m} / \mathrm{z}$ $446[\mathrm{M}+1](3.37 \%)$. Anal. Calcd for $\mathrm{C}_{25} \mathrm{H}_{15} \mathrm{~N}_{7} \mathrm{~S}$ (445.50): C, 67.40; H, 3.39; N, 22.01; S, 7.20. Found: C, 67.78; H, 3.65; N, 22.38; S, 7.57.

5-Amino-3-(anthracen-9-yl)-1-phenyl-1Hpyrazole-4-carboxamide (22).

To a solution of $1 \mathrm{a}(0.01 \mathrm{~mol}, 3.6 \mathrm{~g})$ in ethanol $(30 \mathrm{ml})$, ammonium solution $(50 \mathrm{ml})$ and hydrogen peroxide $(10 \mathrm{ml})$ were added. The reaction mixture was stirred at room temperature for $3 \mathrm{~h}$. The solid that obtained was collected by filtration, washed with water and recrystallized from ethanol to obtain the amide derivative 22 .

m.p. $200-202^{\circ} \mathrm{C}$. IR $(\mathrm{KBr}) v \mathrm{~cm}^{-1}: 3432,3301$ $\left(\mathrm{NH}_{2}\right), 3074,3049$ (CHar), $1676(\mathrm{C}=\mathrm{O}), 1620$ $(\mathrm{C}=\mathrm{N}) .{ }^{1} \mathrm{H}-\mathrm{NMR}\left(400 \mathrm{MHz}, \mathrm{DMSO}-\mathrm{d}_{6}\right) \delta: 6.78-$ 8.76 (m, $14 \mathrm{H}, \mathrm{Ar}-\mathrm{H}), 9.09$ (s, 2H, $\mathrm{NH}_{2}, \mathrm{D}_{2} \mathrm{O}$ exchangeable), 10.65 (s, $2 \mathrm{H}, \mathrm{NH}_{2}, \mathrm{D}_{2} \mathrm{O}$ exchangeable). MS: m/z $378\left[\mathrm{M}^{+}\right](5.91 \%)$. Anal. Calcd for $\mathrm{C}_{24} \mathrm{H}_{18} \mathrm{~N}_{4} \mathrm{O}$ (378.43): C, 76.17; $\mathrm{H}, 4.79 ; \mathrm{N}$, 14.81. Found: C, 75.88; H, 5.02; N, 15.18.
Biological assessment

a) Antimicrobial Activity

The antimicrobial activity of the tested compounds was determined using the disc diffusion technique $[24,25]$ by preparing discs containing $1.9-1000 \mu \mathrm{g} / \mathrm{ml}$ of each compound against gram positive Staphylococcus aureus, Bacillus subtilis and gram negative Escherichia coli, Pseudomonas aeuroginosa. The anti-fungal activities of the compounds were tested against two fungi Candida albicans, Aspergillus flavus. Different dilutions were prepared. The plates were incubated at $37^{\circ} \mathrm{C}$ for $24 \mathrm{~h}$. for bacteria and at $28^{\circ} \mathrm{C}$ for $72 \mathrm{~h}$ for fungi. The standard antibiotic ampicillin and antifungal colitrimazole were used as references. At the end of the incubation period, the minimum inhibitory concentrations (MIC) values were recorded (Table 1) as the lowest concentration of the substance that had no visible turbidity. Control experiments with DMSO and uninoculated media were run parallel to the test compounds under the same conditions.

The results demonstrate that tested fungi were more sensitive to all compounds compared with bacteria. The most active compounds against fungi were $17 \mathrm{~b}$ and 22 . While for bacteria, $8 \mathrm{a}, 8 \mathrm{~b}, 9 \mathrm{~b}, 20$ and 22 for Gram negative and for $1 \mathrm{~b}, 8 \mathrm{a}, 8 \mathrm{~b}, 9 \mathrm{~b}, 17 \mathrm{~b}, 20$ and 22 Gram positive. In addition, Gram negative bacteria were more sensitive to the compounds compared with Gram positive ones.

b) Cytotoxicity assay

Materials and methods

Cell line

Some of the synthesized compounds were tested against two human tumor cell lines name-

$\square$ E. coli $\mathbf{Q}$. aeruginosa S. aureus $₫$ B. subtilis

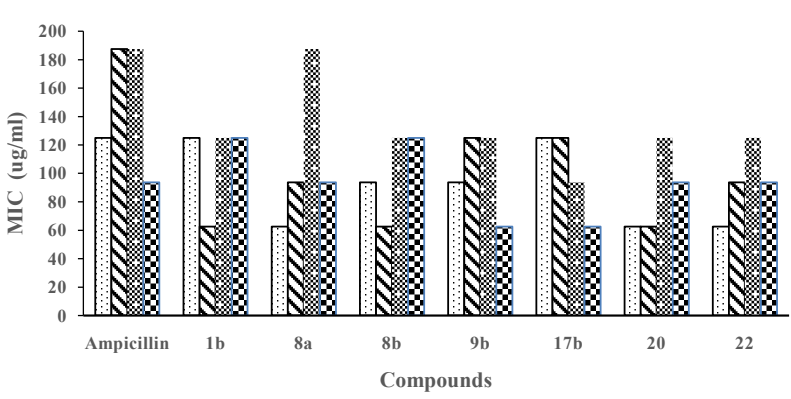

Fig 1: MIC of most potent compounds against bacteria 
Galal H. Sayed, et al.

ly; mammary gland breast cancer (MCF-7) and human skin cancer (HFB4). The cell line were obtained from ATCC via Holding company for biological products and vaccines (VACSERA), Cairo, Egypt.

Chemical reagents

The reagents RPMI-1640 medium, MTT, DMSO and 5-fluorouracil (sigma co., St. Louis,
USA), Fetal Bovine serum (GIBCO, UK). 5-fluorouracil was used as a standard anticancer drug for comparison.

\section{MTT assay}

The different cell lines mentioned above were used to determine the inhibitory effects of compounds on cell growth using the MTT assay $[26,27]$. This colorimetric assay is based on the

Table 1: Antimicrobial and Antimycotic Activities in terms of MIC $(\mu \mathrm{g} / \mathrm{mL})$.

\begin{tabular}{|c|c|c|c|c|c|c|}
\hline Compound & E. coli & $\begin{array}{c}\text { Pseudomonas } \\
\text { aeruginosa }\end{array}$ & S. aureus & B. subtilis & C. Albicans & A. flavus \\
\hline $1 \mathrm{a}$ & 125 & 93.7 & 187.5 & 187.5 & 11.7 & 7.8 \\
\hline $1 \mathrm{~b}$ & 125 & 62.5 & 125 & 125 & 7.8 & 11.7 \\
\hline 2 & NA & 750 & NA & NA & 187.5 & 125 \\
\hline 3 & NA & NA & NA & NA & 250 & 125 \\
\hline 4 & NA & NA & NA & NA & 187.5 & 93.7 \\
\hline 5 & NA & 500 & 750 & 500 & 93.7 & 46.9 \\
\hline 6 & 750 & 500 & NA & 750 & 125 & 93.7 \\
\hline $7 \mathrm{a}$ & 93.7 & 93.7 & 250 & 187.5 & 15.6 & 11.7 \\
\hline $7 \mathrm{~b}$ & NA & 750 & NA & 500 & 93.7 & 46.9 \\
\hline $8 \mathrm{a}$ & 62.5 & 93.7 & 187.5 & 93.7 & 7.8 & 11.7 \\
\hline $8 \mathrm{~b}$ & 93.7 & 62.5 & 125 & 125 & 15.6 & 11.7 \\
\hline $9 \mathrm{a}$ & 250 & 250 & 375 & 250 & 31.2 & 15.6 \\
\hline $9 b$ & 93.7 & 125 & 125 & 62.5 & 11.7 & 11.7 \\
\hline 10 & 250 & 187.5 & 375 & 250 & 23.4 & 15.6 \\
\hline 11 & 500 & 375 & 750 & 500 & 62.5 & 31.2 \\
\hline 12 & NA & NA & 750 & 750 & 125 & 62.5 \\
\hline $13 \mathrm{a}$ & 375 & 250 & 500 & 375 & 31.2 & 23.4 \\
\hline $13 \mathrm{~b}$ & 250 & 500 & 375 & 250 & 62.5 & 31.2 \\
\hline 14 & 750 & 375 & NA & 750 & 125 & 62.5 \\
\hline $15 \mathrm{a}$ & 250 & 187.5 & 375 & 250 & 46.9 & 23.4 \\
\hline $15 \mathrm{~b}$ & 375 & 250 & 250 & 375 & 31.2 & 62.5 \\
\hline 16 & 125 & 187.5 & 187.5 & 125 & 15.6 & 11.7 \\
\hline $17 \mathrm{a}$ & 187.5 & 125 & 250 & 187.5 & 23.4 & 11.7 \\
\hline $17 \mathrm{~b}$ & 125 & 125 & 93.7 & 62.5 & 5.8 & 5.8 \\
\hline $18 \mathrm{a}$ & 187.5 & 187.5 & 250 & 187.5 & 15.6 & 15.6 \\
\hline $18 \mathrm{~b}$ & 250 & 250 & 187.5 & 93.7 & 11.7 & 11.7 \\
\hline $19 \mathrm{a}$ & 375 & 250 & 500 & 375 & 46.9 & 23.4 \\
\hline $19 \mathrm{~b}$ & 500 & 375 & 250 & 250 & 31.2 & 62.5 \\
\hline 20 & 62.5 & 62.5 & 125 & 93.7 & 5.8 & 7.8 \\
\hline 21 & 375 & 250 & 500 & 375 & 62.5 & 31.2 \\
\hline 22 & 62.5 & 93.7 & 125 & 93.7 & 7.8 & 5.8 \\
\hline Ampicillin & 125 & 187.5 & 187.5 & 93.7 & ---- & ---- \\
\hline Colitrimazole & ---- & ---- & ---- & ---- & 7.8 & 5.8 \\
\hline
\end{tabular}




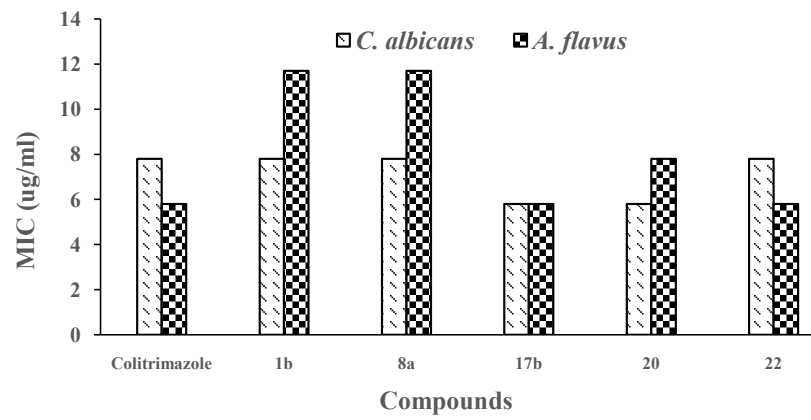

Fig 2: MIC of most potent compounds against fungi conversion of the yellow tetrazolium bromide (MTT) to a purple formazan derivative by mitochondrial succinate dehydrogenase in viable cells. The cells were cultured in RPMI-1640 medium with $10 \%$ fetal bovine serum. Antibiotics added were $100 \mathrm{units} / \mathrm{ml}$ penicillin and $100 \mu \mathrm{g} / \mathrm{ml}$ streptomycin at $37 \mathrm{C}$ in a $5 \% \mathrm{Co}_{2}$ incubator. The cells were seeded in a 96 -well plate at a density of $1.0 \times 104$ cells/well [25] at $37 \mathrm{C}$ for $48 \mathrm{~h}$ under $5 \% \mathrm{Co}_{2}$. After incubation the cells were treated with different concentration of compounds and incubated for $24 \mathrm{~h}$. After $24 \mathrm{~h}$ of drug treatment, $20 \mu 1$ of MTT solution at $5 \mathrm{mg} / \mathrm{ml}$ was added and incubated for $4 \mathrm{~h}$. Dimethyl sulfoxide (DMSO) in volume of $100 \mu \mathrm{l}$ is added into each well to dissolve the purple formazan formed. The colorimetric assay is measured and recorded at absorbance of $570 \mathrm{~nm}$ using a plate reader (EXL

Table 2: Cytotoxic activity of some compounds against human tumor cells

\begin{tabular}{|c|c|c|}
\hline \multirow{2}{*}{ Compounds } & \multicolumn{2}{|l|}{ In vitro Cytotoxicity IC50 $(\mu \mathrm{g} / \mathrm{ml})$} \\
\cline { 2 - 3 } & MCF7 & HFB4 \\
\hline 5 -FU & $5.4 \pm 0.20$ & $8.8 \pm 0.52$ \\
\hline $1 \mathrm{a}$ & $10.5 \pm 0.92$ & $13.4 \pm 1.08$ \\
\hline 2 & $64.9 \pm 4.03$ & $95.6 \pm 5.24$ \\
\hline 5 & $55.7 \pm 3.75$ & $71.1 \pm 4.37$ \\
\hline $8 \mathrm{~b}$ & $8.2 \pm 0.67$ & $19.4 \pm 1.53$ \\
\hline $9 \mathrm{a}$ & $38.1 \pm 2.80$ & $32.2 \pm 2.64$ \\
\hline 12 & $82.4 \pm 4.58$ & $85.7 \pm 4.76$ \\
\hline $15 \mathrm{a}$ & $32.8 \pm 2.44$ & $46.8 \pm 3.15$ \\
\hline $17 \mathrm{~b}$ & $16.0 \pm 1.14$ & $7.8 \pm 0.57$ \\
\hline $17 \mathrm{a}$ & $20.5 \pm 1.56$ & $26.6 \pm 2.12$ \\
\hline 21 & $45.8 \pm 3.11$ & $54.3 \pm 3.79$ \\
\hline 22 & $5.2 \pm 0.39$ & $9.8 \pm 0.86$ \\
\hline
\end{tabular}

- IC50 ( $\mu \mathrm{g} / \mathrm{ml})$ : 1 - 10 (very strong). 11 - 20 (strong). 21 - 50 (moderate). $51-100$ (weak) and above 100 (non-cytotoxic) , 5-FU = 5-fluorouracil.
800 , USA). The relative cell viability in percentage was calculated as (A570 of treated samples/ A570 of untreated sample) X 100. The results of cytotoxic activity of the tested compounds are listed, in terms of $\mathrm{IC}_{50}(\mathrm{mg} / \mathrm{ml})$, in table 2 .

The results in table 2 revealed that compounds $8 \mathrm{~b}, 22$ showed very strong cytotoxic activity and compounds 1a, 17a showed strong cytotoxic activity against (MCF7), while compounds 17b, 22 showed very strong cytotoxic activity and compounds $1 \mathrm{a}, 8 \mathrm{~b}$ showed strong cytotoxic activity against (HFB4).

\section{Conclusion}

In this paper the enaminonitriles $1 \mathrm{a}, \mathrm{b}$ were used as a key starting materials to synthesize a variety of heterocyclic ring systems containing mainly a pyrazole moiety. The newly synthesized compound were tested against gram positive Staphylococcus aureus, Bacillus subtilis and gram negative Escherichia coli, Pseudomonas aeuroginosa, two fungi Candida albicans, Aspergillus flavus and two human tumor cell lines namely; mammary gland breast cancer (MCF7) and human skin cancer (HFB4). Some of the tested compounds showed a high antimictobial and very strong cytotoxic activities.

\section{REFERENCES}

Rashed, A. E., Hegab, M. I., Abdel-Megeid, R. E., Fathalla, N. and Abdel-Megeid, F. M. E, (2009). Synthesis and anti-HSV-1 evaluation of some pyrazoles and fused pyrazolopyrimidines. Eur. J. Med. Chem., 44: 32853292.

Sidduri, A., Budd, D. C., Fuentes, M. E., Lambros, T., Ren, Y., Roongta, V., Schoenfeld, R. C., Gillespie, P., Stevenson, C. S., Triut, T., and Qian, Y., (2014). Discovery of novel non-carboxylic acid 5-amino-4-cyanopyrazole derivatives as potent and highly selective LPA1R antagonists. Bioorg. Med. Chem. Lett., 24: 4450-4454.

Abdel-Aal, M. T., Abdel-Aleem, A. H., Ibrahim, L. I. and Rein, A. I., (2010). Synthesis and antimicrobial activity of novel 5-amino-4-cyano-1H-pyrazole and quinazolin-4(3H)-one derivatives. Arch. Pharm. Res., 33: 1891-1900. Rahmouni, A., Romdhane, A., Ben Said, A.; Majuli, K. and Ben Jannet, H., (2014). Synthesis of new pyrazole and antibacterial pyrazolopyrimidine derivatives. Turk. J. Chem., 38: 210-222.

Sondhi, S. M., Kumar, S., Kumar, N. and Roy, P., (2012). Synthesis anti-inflammatory and anticancer activity evaluation of some pyrazole and oxadiazole derivatives. Med. Chem. Res., 21: 3043-3052.

Nayak, P. S., Narayana, B., Sarojini, B. K., Fernades, J., 
Bharath, B. R. and Madhu, L. N., (2015). Synthesis, molecular docking and biological evaluation of novel bis-pyrazole derivatives for analgesic, anti-inflammatory and antimicrobial activities. Med. Chem. Res., 24: 4191-4206.

Bahashwan, S. A., Fayed, A. A., Ramadan, M. A., Amr, A. E. and Al-Harbi, N. O., (2014). Androgen Receptor Antagonists and Anti-Prostate Cancer Activities of Some Newly Synthesized Substituted Fused Pyrazolo-, Triazolo- and Thiazolo-Pyrimidine Derivatives. Int. J. Mol. Sci., 15: 21587-21602.

Meazza, G., Bettarini, F., La Porta, P., Piccardi, P., Signorini, E., Portoso, D. and Fornara, L., (2004). Synthesis and herbicidal activity of novel heterocyclic protoporphyrinogen oxidase inhibitors. Pest Manag. Sci., 60: 1178-1188.

Jiang, D. X., Zheng, X. H., Shao, G., Ling, Z. and Xu, H. H., (2014). Discovery of a Novel Series of Phenyl Pyrazole Inner Salts Based on Fipronil as Potential Dual-Target Insecticides. J. Agric. Food Chem., 62: 3577-3583.

Xiao, J. J., Liao, M., Chu, M. J., Ren, Z. L., Zhang, X., Lv, X. H. and Cao, H. Q., (2015). Design, Synthesis and Anti-Tobacco Mosaic Virus (TMV) Activity of 5-Chloro-N-(4-cyano-1-aryl-1H-pyrazol-5-yl)-1-aryl3-methyl-1H-pyrazole-4-carboxamide Derivatives. Molecules, 20: 807-821.

Penning, T. D., Talley, J. J., Bertenshaw, S. R., Carter, J. S., Collins, P W., Docter, S., Graneto, M. J., Lee, L. F., Malecha, J. W., Miyashiro, J. M., Rogers, R. S., Rogier, D. J., Yu, S. S., Anderson, G. D., Burton, E. G., Cogburn, J. N., Gregory, S. A., Koboldt, C. M., Perkins, W. E., Seibert, K., Veenhuizen, A. W., Zhang, Y. Y. and Isakson, P. C., (1997). Synthesis and Biological Evaluation of the 1,5-Diarylpyrazole Class of Cyclooxygenase-2 Inhibitors: Identification of 4-[5-(4-Methylphenyl)-3- (trifluoromethyl)-1H-pyrazol-1-yl]benzenesulfon-amide (SC-58635, Celecoxib). J. Med. Chem., 40: 1347-1365.

Goel, N., Drabu, S., Afzal, O. and Bawa S., (2014). Antimicrobial screening and one-pot synthesis of 4-(substituted-anilinomethyl)-3-(2-naphthyl)-1-phenyl-1Hpyrazole derivatives. J. Phar. and Bio. Sci., 6:253-260.

Ryan, W. G., Carithers, D., Moldave, K. and Bell, M., (2010). Field comparison of canine NSAIDs firocoxib and deracoxib. Int. J. Appl. Res. Vet. Med., 8: 114-123.

El-Hashash, M. A., Azab, M. E. and Morsy, J. M., (2016). One-Pot Synthesis of Some Dynamic 2-Substitued Benzoxazinones and Their Corresponding Quinazolinones of Anticipated Biological Activity. J. Het. Chem., 53: 95-101.

El-Hashash, M. A., Morsy, J. M., Azab, M. E. and Mahmoud, N. F., (2016). Design, synthesis and anticancer activity of novel 2,3- and 2,4-disubstituted quinazoline and quinazolinone derivatives. Heterocycles, 92: 316329.
El-Hashash, M. A., Azab M. E., Abd El-Aziz, F. R. and Amr, A. E., (2016). Synthesis, antimicrobial and antiinflammatory activity of some new benzoxazinone and quinazolinone candidates. Chem. Pharm. Bull., 64: 263-271.

Azab, M. E., Rizk, S. A. and Mahmoud, N. F., (2016). Facile Synthesis, Characterization and Antimicrobial Evaluation of Novel Heterocycles, Schiff Bases and N-Nucleosides Bearing Phthalazine Moiety. Chem. Pharm. Bull., 64: 339-350.

Hasaninejad, A. and Firoozi, S., (2013). Catalyst-free, one-pot, three-component synthesis of 5-amino-1,3aryl-1H-pyrazole-4-carbonitriles in green media. Mol. Diversity, 17: 459-469.

T. Yoshinari, M. Yoshiki, O. Yukio; U. Yoshimitsu, K. Hirofumi; et al., (1990). Polarized ethylenes. IV. Synthesis of polarized ethylenes using thioamides and methyl dithiocarboxylates and their application to syntheses of pyrazoles, pyrimidines, pyrazolo[3,4-d]pyrimidines, and 5-aza[2.2.3]cyclazines J. Het. Chem., 27: 647-660.

Murray, P. R., Baron, E. J., Pfaller, M. A., Tenover, F.C., Yolken R. H., wood, G. L., Washington, J. A. (Eds.), Manual of Clinical Microbiology, Am. Soc. Microbiol., Washington, DC, 1995.

M. S. T. Makki, D. A. Bakhotmah, R. M. Abdal-Rahman and M. S. El-shahowy, (2012). Int. J. Org. Chem., 2: 311-320.

S. A. S. Bahashwar, A. A. Fayed, M. A. Ramadan, Abd El-al and N.O. Al-Harbi, (2014). Androgen Receptor Antagonists and Anti-Prostate Cancer Activities of Some Newly Synthesized Substituted Fused Pyrazolo-, Triazolo- and Thiazolo-Pyrimidine Derivatives, Int. J. Mol., 5: 21587-21602.

Y. Tominaga, Y. Hankowa, M. Hara and A. Hosomit, (1990). Synthesis of pyrazolo[3,4-d]pyrimidine derivatives using ketene dithioacetals, J. Het. Chem., 27: 775-783

Hanging, et al., (2001). 1,5-Dihydroxy-pyrazolo[34-D]pyrimidinone derivatives, untited state patents, 12: 1-37

Jones, R. N., Barry, A. L., Gavan, T. L., Washington, I. I. A., Lennette, E. H., Ballows, A., Hausler, W. J. Jr. and Shadomy H. J. (Eds.), Manual of Clinical Microbiology, fourth ed, Am. Soc. Microbiol. (1972), Washington DC, 1985.

Mosmann, T., Rapid colorimetric assay for cellular growth and survival: Application to proliferation and cytotoxicity assays, (1983). J. Immunol. Methods, 65: 55-63.

Denizot, F. and Lang, R., (1986). Rapid colorimetric assay for cell growth and survival: Modifications to the tetrazolium dye procedure giving improved sensitivity and reliability. J. Immunol. Methods, 22: 271-277.

Mauceri, H. J., Hanna, N. N., Beckett, M. A., Gorski, D. H., Staba, M. J., Stellato, K. A., Bigelow, K., Heimann, R., Gately, S., Dhanabal, M., Soff, G. A., Sukhatme, V. P., Kufe, D. W., Weichselbaum, R. R., (1998). Combined effects of agiostatin and ionizing radiation in antitumor therapy. Nature, 394: 287-291 